SAKAI SAMBAYAN — Jurnal Pengabdian kepada Masyarakat

\title{
PEMANFAATAN PEMBERIAN GEL COLLOID BUAH POHON AREN (Arenga pinnata Merr) YANG DIKONSUMSI SEBAGAI TERAPI OSTEOARTHRITIS GENU TERHADAP MANULA DI UPTD PSLU TRESNA WERDHA
}

\author{
Rodhiansyah Djayasinga ${ }^{1 *}$, Sri Ujiani ${ }^{1,}$ Misbahul Huda ${ }^{2}$, Sri Nuraini ${ }^{2}$, \\ Eka Sulistiyaningsih ${ }^{1}$,Mimi Sugiarti ${ }^{1}$, Nurminha ${ }^{1}$ \\ ${ }^{\text {I}}$ ProdiDiploma IV JurusanAnalisPoltekkesTanjungkarang \\ ${ }^{2}$ Prodi Diploma III Jurusan Analis Poltekkes Tanjungkarang \\ Jln. Soekarno-Hatta No. 1 Hajimena Bandar Lampung \\ Penulis Korespodensi : djayasinga85@gmail.com
}

\begin{abstract}
Abstrak
Kegiatan Pengabdian Kepada Mayarakat ini adalah sebagai penerapan salah satu Tri Dharma Perguruan Tinggi yang dilakukan pada UPTD PSLU Tresna werdha Kecamatan Natar Kabupaten Lampung Selatan berdasarkan pengumpulan data melalui skala nyeri bahwa terdapat banyak keluhan osteoarthritis genu pada manula dengan derajat kesakitan pada level sedang. Solusi yang diberikan oleh Tim Pengabmas Poltekkes Tanjungkarang adalah memberikan buah aren sebanyak $100 \mathrm{~g} / \mathrm{orang} / \mathrm{hari}$ selama 2 (dua) bulan dan peralatan blender untuk mebuat buah aren menjadi bentuk gel colloid sebagai terapi osteoarthritis genu. Penyampaian informasi dan cara pengolahan buah aren melibatkan para manula dengan tujuan agar keluhan osteoarthritis genu menjadi berkurang pada skala nyeri dan timbul kesadaran atau kemauan dari para manula untuk mengkonsumsi buah aren dalam mengobati osteoarthritis genu. Hasil yang didapat adalah terjadi perubahan sebesar $100 \%$ yakni keluhan osteoarthritis genu pada skala nyeri pada awalnya 10 orang manula dengan tingkat nyeri sedang, setelah mengkonsumsi buah aren 100 gr/hari/orang selama 2 (dua) bulan, keluhan nyeri setingkat sedang menjadi pada tingkat ringan.
\end{abstract}

Kata kunci: Buah Pohon Aren (ArengapinnataMerr), Manula, Osteoarthritis genu

\section{Pendahuluan}

Osteoarthritis (OA) merupakan jenis gangguan persendian yang sering dikeluhkan oleh pasien (Cote, 2001:495). Organisasi Kesehatan Dunia (WHO) melaporkan bahwa osteoarthritis lutut merupakan penyebab disabilitas keempat pada perempuan dan kedelapan pada laki-laki (Cote, 2001: 496). Saxon et al (1999:124) memperkitakan sepertiga orang yang berusia 25 sampai dengan 75 tahun mempunyai gambaran osteoarthrtitis sendi pada pemeriksaan radiologs. Lutut merupakan persendian yang paling sering mengalami osteoarthritis dan merupakan jenis osteoarthritis yang paling berkaitan dengan gejala nyeri dan disabilitas (Baker, 2000;217).

Penatalaksanaan nyeri pada OA dapat dilakukan dengan obat konvensional yang sudah ada, dimulai dengan analgetik sederhana sampai obat inflamasi non steroid (OAINS). Beberapa OAINS dilaporkan cukup efektif dalam mengatasi nyeri kronis penderita OA lutut, akan tetapi OAINS dapat menyebabkan efek samping misalnya perdarahan gastrointestinal atau gangguan pada ginjal.

Penggunaan bahan alam, baik sebagai obat maupun tujuan lain cenderung meningkat, terlebih dengan adanya pemikiran mengunakan obat alami serta krisis berkepanjangan yang mengakibatkan turunnya daya beli masyarakat. Indonesia sebagai Negara tropis memiliki kekayaan tanaman obat. Salah satu tanaman yang dimanfaatkan untuk pengobatan tradisional adalah buah pohon aren (Suherry, dkk, 2014).

Khasiat buah aren / kolang kaling dapat memperkuat tulang, memperlancar pencernaan, penyedia serat pangan (dietary fiber0, meredakan radang pada sendi. Manfaat buah aren / kolang kaling dapat meredakan radang sendi disebabkan karena buah pohon aren / kolang kaling mengandung zat galaktomanan yang bisa meredakan nyeri radang sendi. Untuk kesehatan sendi mengkonsumsi secara rutin minimal 100 
gram kolang kaling setiap hari dengan cara merebus kolang kaling tanpa gula dan tanpa pewarna, (Purwati dkk, 2018).

Pelayanan Sosial Lanjut Usia (PSLU) Tresna Werdha merupakan merupakan salah satu ujung tombak Dinas Sosial Kabupaten Lampung Selatan memiliki lintas koordinasi dengan Unit Rehabilitasi Sosial, selanjutnya unit ini berkordinasi dengan seksi anak dan lanjut usia, dalam melaksanakan tugas dan memiliki fungsi menampung dan merawat kehidupan para Manusia Lanjut Usia (Manula).

Analisa situasi yang dilakukan oleh Tim Pengabdian Masyarakat (Pengabmas) dosen Poltekkes Tanjungkarang pada kegiatan Pengabdian Kepada Masyarakat di unit Pelayanan Sosial Lanjut Usia (PSLU) Tresna Werdha dapat diuraikan sebagai berikut, PSLU Tresna Werdha beralamat di Jalan Sitara Desa Muara Putih Kecamatan Natar Kabupaten Lampung Selatan. PSLU Tresna Werdha.

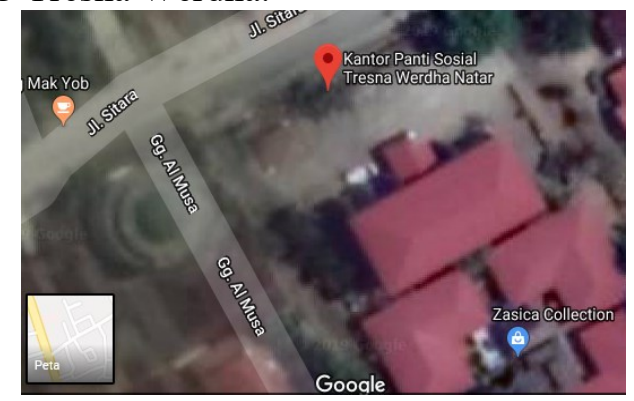

Gambar 1. Peta Lokasi PSLU Tresna Werdha

Jumlah Manula yang menghuni PSLU Tresna Werdha tahun 2018 sebanyak 85 jiwa, terdiri dari 38 manula pria dan 47 manula wanita. PSLU Tresna Werdha memiliki 14 (empat belas) wisma hunian, dimana 11 wisma diperuntukkan bagi hunian manula mandiri dan 3 (tiga) wisma diperuntukkan bagi manula tidak mandiri. Ruang hunian manula pria terpisah dengan manula wanita.

Permasalahan manula penghuni wisma PSLU Tresna Werdha antara lain; (1) keluhan nyeri sendi lutut (Osteoarthritis genu); (2) konsumsi jenis makanan atau minuman untuk pemeliharaan dan pemulihan kesehatan pada penyakit Osteoarthritis genu belum rutin diberikan; (3) Pengetahuan jenis makanan buah pohon aren untuk pemeliharaan dan pemulihan kesehatan pada penyakit Osteoarthritis genu belum banyak diketahui; (5) rutinitas manula dalam melakukan kegiatan olahraga seringkali sulit terlaksana.
Terhadap permasalahan keluhan penyakit degeneratif osteoarthritis genupada manula di PSLU Tresna Werdha, Tim Pengabmas Poltekkes Tanjungkarang Jurusan Analis Kesehatan memiliki solusi yaitu;(1) memberikan sejumlah suplemen berupa makanan tambahan dari bahan alam yaitu buah pohon aren kepada 10 orang manula yang menempati wisma kenanga untuk dikonsumsi setiap hari (@70 gram/10 butir/hari) selama selama 2 (dua) bulan ;(2) memberikan sarana berupa mesin blender untuk digunakan membuat buah aren menjadi bentuk gel colloid;(3) melibatkan para manula mandiri dalam menyiapkan cara penyajian suplemen dalam bentuk gel coloid tersebut agar efektif dalam pemulihan penyakit degeneratif osteoarthritis; (4) melibatkan para manula mandiri agar dalam mengolah buah aren untuk dikosumsi oleh mereka.

Target luaran kegiatan pengabmas ini seperti tertulis pada Tabel 1 dibawah ini;

Tabel 1. Target Luaran Pengabmas

\begin{tabular}{|c|c|c|}
\hline No & Jenis Luaran & $\begin{array}{c}\text { Indikator } \\
\text { Capaian }\end{array}$ \\
\hline \multicolumn{3}{|c|}{ Luaran Wajib } \\
\hline 1. & $\begin{array}{l}\text { Peningkatan Pengetahuan } \\
\text { manula mandiri dalam } \\
\text { mengobati penyakit } \\
\text { degeneratif osteoarthritis } \\
\text { genumenggunakan buah } \\
\text { poho aren berwujud gel } \\
\text { colloid }\end{array}$ & Tercapai \\
\hline 2. & $\begin{array}{l}\text { Peningkatan kemampuan } \\
\text { manula mandiri dalam } \\
\text { membuat gel colloidbuah } \\
\text { aren menggunakan mesin } \\
\text { blender }\end{array}$ & Tecapai \\
\hline 3 & $\begin{array}{l}\text { Memberikan } 1 \text { (satu) unit } \\
\text { mesin bleder untuk } \\
\text { membuat gel colloid buah } \\
\text { aren }\end{array}$ & Tercapai \\
\hline 4. & $\begin{array}{l}\text { Memberikan buah pohon } \\
\text { aren untuk diubah menjadi } \\
\text { bentuk gel colloid }\end{array}$ & Tercapai \\
\hline & Publikasi pada repocitory & \\
\hline 5. & Poltekkes Tanjungkarang & Tercapai \\
\hline \multicolumn{3}{|c|}{ Luaran Tambahan } \\
\hline 1. & $\begin{array}{l}\text { Inovasi Teknologi Tepat } \\
\text { Guna } \\
\text { Jasa: rekayasa sosial, } \\
\text { Metode atau sistem, } \\
\text { produk/barang }\end{array}$ & Tercapai \\
\hline
\end{tabular}




\section{Metode Pelaksanaan}

Metode pelaksanaan yang diterapkan dalam kegiatan pengabmas ini terdiri dari beberapa tahap yaitu;

\section{A. Survey Lapangan.}

Sebelum kegiatan dilaksanakan terlebih dahulu dilakukan penjajakan ke PSLU Tresna Werdha Kecamatan Natar Lampung Selatan untuk memperoleh data jumlah hunian manula, jumlah pasien penderita OA genu, sertasaranadanprasarana yang tersedia.

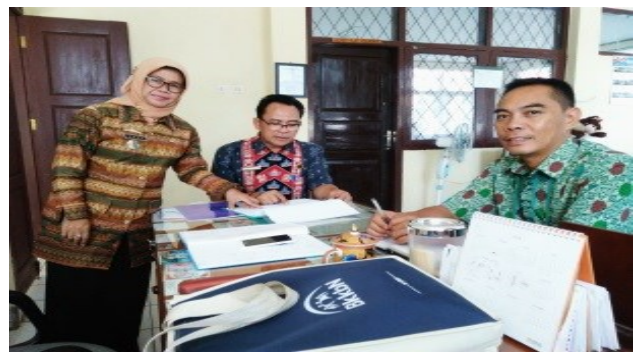

Gambar 2. Tahapan Penjajakan Pengabmas ke PSLU Tresna Werdha

\section{B. Koordinasi dengan Pihak PSLU Tresna Werdha \\ Koordinasi dilakukan dengan pihak PSLU} Tresna Werdha Kecamatan Natar Lampung Selatan dengan meminta ijin terlebih dahulu untuk dilakukannya kegiatan pengabdian masyarakat oleh dosen Poltekkes Tanjungkarang Jurusan Analis Kesehatan Program Studi Diploma IV. Disepakati jadwal dan pembagian tugas pelaksanaan kegiatan dari pihak Politeknik Kesehatan Tanjungkarang dan pihak PSLU Tresna Werdha Kecamatan Natar Lampung Selatan.

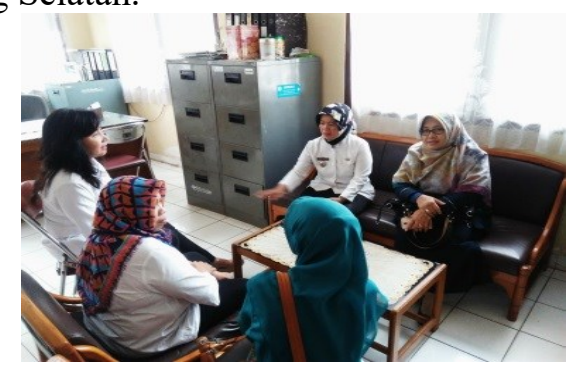

Gambar 3. Koordinatsi Tim Pengabmas bersama Pengelola PSLU Tresna Werdha

\section{Sosialisasi Program}

Sosialisasi program dengan mengirimkan surat pemberitahuan kepada pengelola PSLU Tresna Werdha bahwa dalam kegiatan Pengabmas akan ada edukasi dalam praktek mengajarkan manula cara mengolah buah pohon aren menjadi bubur lembut hingga memudahkan dalam mengkonsumsi buah tersebut yang berguna untuk mengurangi rasa sakit sebagai akibat dari Osteoarthritis genu.

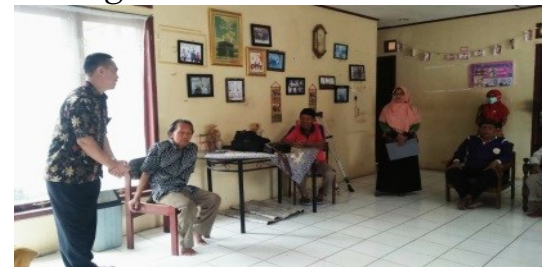

Gambar 4. Sosialisasi Program Pengabmas

\section{Pelaksanaan Program}

Tahapan pelaksanaan dalam kegiatan

Pengabmas ini adalah;

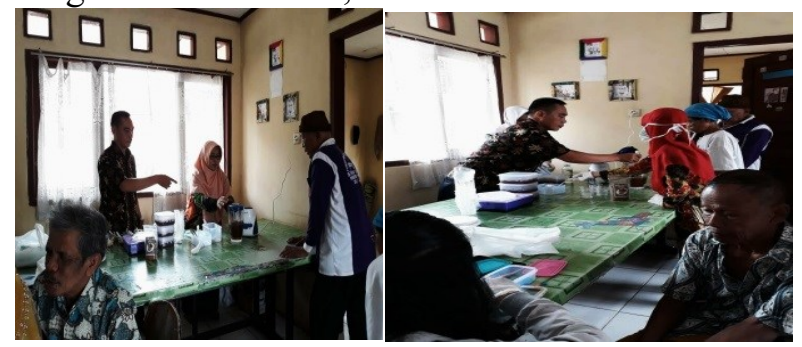

Gambar 5 dan 6. Proses edukasi pembuatan colloid gel kolang-kaling kepada para Manula

1. Berkoordinasi antar anggota Tim Pengabmas melalui rapat dalam menentukan jumlah wisma manula mandiri yang akan menjadi target intervensi

2. Berkoordinasi dengan mitra PSLU Tresna werdha guna memaparkan tahapan kegiatan Pengabmas Poltekkes Tanjungkarang Jurusan Analis dalam kaitannya dengan penanganan penyakit osteoarthritis genu pada manula mandiri.

3. Melakukan kegiatan pengumpulan data jumlah penderita osteoarthritis genu melalui gambaran klinis dengan cara Tanya jawab menggunakan kuesioner antara Tim Pengabmas dengan para manula mandiri

4. Melakukan rapat antar Tim Pengabmas terhadap data yang diperoleh, untuk selanjutnya melaksanakan solusi yang direncanakan,

5. Solusi yang dilakukan ini berupa kegiatan antara lain;

a) Memberikan sejumlah buah pohon aren dan alat blender kepada pihak PSLU TresnaWerdha untuk ditujukan pada pemulihan kesehatan penyakit osteoarthritis genu pada manula mandiri

b) Memberikan pengetahuan takaran penyajian gel colloid buah pohon aren 
untuk dikonsumsi manula, yaitu $100 \mathrm{~g}$ (10 butirbuaharen)/manula/hari. $100 \mathrm{~g}$ buah aren yang telah direbus dengan air mendidih, kemudian di blender dan ditambahkan gula aren sebagai pemanis secukupnya, dimana setelah diblender kemudian dikonsumsi dengan interval waktu 2 kali yaitu, pagi sebelum makan $50 \mathrm{~g}$ dan malam hari sebelum tidur $50 \mathrm{~g}$.

c) Pengolahan buah aren di atas melibatkan para manula mandiri dalam pembuatannya dengan tujuan agar para manula selanjutnya mampu mengolah sendiri buah aren tersebut

d) Anjuran konsumsi buah aren di atas disarankan untuk dikonsumsi selama 2 (dua) bulan, oleh karena itu buah aren yang diberikan kepada para manula sebanyak 20 $\mathrm{Kg}$ (untuk dikonsumsi 10 orang manula).

\section{E. Sasaran}

Sasaran kegiatan ini adalah manula penderita penyakit $O A$ genu pada 2 (dua) wisma hunian manula mandiri di PSLU TresnaWerdha.

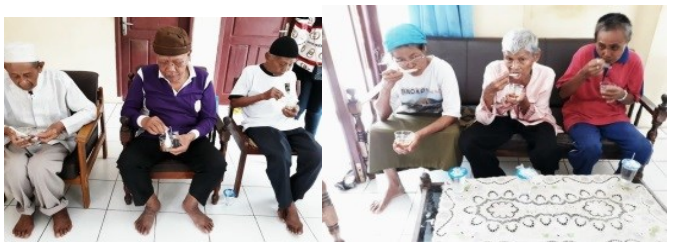

Gambar 7 dan 8.Para Manula Penderita OA sebagai Sasaran Kegiatan Pengabmas

\section{F. Evaluasi}

Evaluasi proses dilakukan dengan menggunakan lembar skala nyeri selama proses kegiatan pengabdian masyarakat terhadap perkembangan kemajuan pengobatan penyakit $O A$ genu yang diderita oleh manula pada PSLU Tresna Werdha.

Evaluasi hasil dilakukan dengan menilai menurunnya tingkat keluhan penyakit $O A$ genu yang didertita oleh manula.

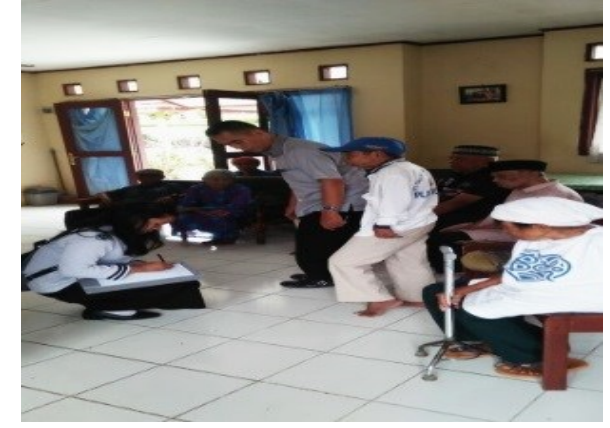

Gambar 9. Pengecekan kemajuan terapi OA

\section{Hasil Yang Dicapai}

Indikator keberhasilan Pengabdian Masyarakat ini adalah; (1) terdapat pengurangan rasa nyeri sebesar $100 \%$ terhadap 10 manula; (2) Manula memiliki pengetahuan tentang pemanfaatan buah kolang kalig untuk mengurangi rasa nyeri sendi (Osteoathritis genu); (3) Manula memiliki kemampuan membuat colloid gel buah kolang kaling.

Berkurangnya keluhan rasa nyeri pada sendi lutut yang dapat diketahui melalui observasi gerakan pada lutut masing-masing manula sebanyak 10 (sepuluh) manula, kemudian keluhan nyeri sendi lutut kaki diukur perkembangan pengurangan rasa sakit melalui skala nyeri, seperti ditunjukkan pada Tabel Hasil Perubahan Keluhan OA Manula Berdasarkan Skala Nyeri (terlampir)

\section{Kesimpulan}

Berdasarkan hasil kegiatan pengabmas yang diperoleh dapat disimpulkan bahwa buah kolang kaling dapat bermanfaat mengurangirasa sakit akibat osteoarthritis genu dengan takaran tertentu. Kegiatan pengabmas ini dapat dilanjutkan kembali mengingat masih banyak manula yang belum mendapatkan edukasi pemanfaatan buah kolang kaling untuk mengurangi rasa nyeri akibat Osteoarthritis genu.

\section{Ucapan Terima Kasih}

Tim Pengabmas Jurusan Analis Kesehatan Poltekkes Tanjungkarang berterima kasih kepada institusi Poltekkes Tanjungkarang yang telah memfasilitasi kegiatan Penngabmas yang dilaksanakan di PSLU Tresna Werdha Kecamtan Natar Kabupaten Lampung Selatan.

\section{Daftar Pustaka}

Baker, K, (2000). "An Update on Exercise Therapy for Knee Osteoarthritis." Nutrition in Clinical Care (Tahun 3, Nomor 4) Hlm.216-224. 
Cote, L, G, (2001).”Management Osteoarthritis.” Journal of the American Academy of Nurse Practitioners (Tahun 13, Nomor 11) hlm.495496.

Purwati, Tutik Nugraheni, 2018. "Pemanfaatan Buah Kolang Kaling Dari Hasil Perkekbunan Sebagai Pangan Fungsional." Jurnal Abdi Mahakam Vol. 2 No. 1. Januari 2018.

Saxon, L, C. Finch and S. Bass (1999). " Sport Participation. Sport Injuries and Osteoarthritis."
Sports Medicine (Tahun 28, Nomor 2) Hlm.123135.

Suherry R, Ah Yusuf, RetnoIndarwati, 2014.PemberianCampuranDaunPandanWangi (Pandanusamaryllifoliusroxb) danVirgin Coconut Oil (VCO) BerpengaruuhTerhadapPenurunanNyeriSendipa daLansiadenganOsteoarthrtitis.Journal community Health Nursing 2(2), 99-105.

\section{Lampiran}

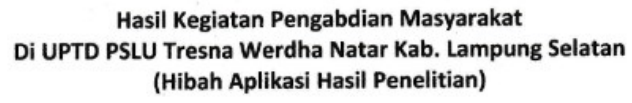

Tabel Hasil Perubahan Keluhan Osteoarthritis genu Manula berdasarkan Skala Nyeri

\begin{tabular}{|c|c|c|c|c|c|c|c|}
\hline \multirow{2}{*}{ No } & \multirow{2}{*}{ Nama Manula } & \multicolumn{3}{|c|}{ Awal (sebelum intervensi) } & \multicolumn{3}{|c|}{ Hasil (setelah intervensi) } \\
\hline & & Ringan & Sedang & Berat & Ringan & Sedang & Berat \\
\hline 1 & Tn. Sukiman & & $v$ & & $\checkmark$ & & \\
\hline 2 & Tn. Suwandi & & $\checkmark$ & & $v$ & $\cdot$ & \\
\hline 3 & Tn. Usman & 3 & $v$ & & $v$ & & \\
\hline 4 & Tn. Mad Rais & & $\checkmark$ & & $\checkmark$ & & \\
\hline 5 & Ny. Sawiyah & & $\mathrm{v}$ & & $\checkmark$ & & \\
\hline 6 & Ny. Harsinah & & $\sqrt{ }$ & & $v$ & & \\
\hline 7 & Ny. Sunikem & & $\checkmark$ & & $\checkmark$ & & \\
\hline 8 & Tn. Rusdi & & $v$ & & $\checkmark$ & & \\
\hline 9 & Tn. Sahari & & $\checkmark$ & & $\checkmark$ & & \\
\hline 10 & Tn. Basiran & & $\checkmark$ & & $\checkmark$ & & \\
\hline
\end{tabular}

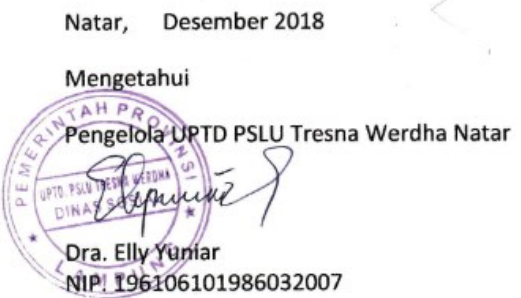

Keterangan;

Skala nyeri ringan: ditandai dengan ada suara gemelutuk ketika sesorang menggerakkan sendi lutut kaki.

Skala nyeri sedang: ditandai dengan rasa nyeri suara gemelutuk dan rasa nyeri ketika sesorang beraktivitas seperti seseorang menaiki atau menuruni anak tangga

Skala nyeri berat: ditandai rasa nyeri yang hebat terus menerus sehingga menyebabkan sesorang tidak bias beraktivitas dengan menggerakkan sendi lutut kakinya, misalnya hanya berbaring atau duduk saja. 